\title{
POR UMA EPISTEMOLOGIA DO CUIDADO DE ENFERMAGEM E A FORMAÇÃO DOS SUJ EITOS DO CONHECIMENTO NA ÁREA DA ENFERMAGEM - DO ÂNGULO DE UMA VISÃO FILOSÓFICAa
}

\author{
For an epistemology of nursing care and the educational \\ development of the subjects of knowledge in nursing area - \\ a philosophical point of view
}

\author{
Por una epistemologia del cuidado de enfermería y la formación de \\ los suj etos del conocimiento en la área de enfermería - Del ángulo \\ de una visión filosófica
}

\author{
Vilma de Carvalho'
}

\begin{abstract}
RESUMO
Sobre Enfermagem - projeto epistêmico/conjunto teórico-axiomático - no Sistema Nightingale de ensino/prática assistencial à saúde e cuidados/enfermos e sadios. Ações/enfermeiras (os) caracterizadas na ética, instruções técnicas, saber moderno rompendo com saber/pré-científico. Enfermagem - disciplina/prática científica - ordenada em esquemas formais/conteúdos materiais aliada ao estilo do cuidado de enfermagem. Abordagem crítico-discursiva-reflexões - cuidado de enfermagem e formação dos sujeitos do conhecimento/ área-da-enfermagem. Do ângulo filosófico, a enfermagem como ciência-em-construção. Cuidado de enfermagem como conceito/atos/ operações/enfermeiras(os), interpretado/inerência epistemológica de idéias - Sistema Nightingale designado solo epistemológico -, concebido/analisado/estrutura/fundo-de-saber e princípios nightingaleanos. Posição/autora contrária ao conceito de cuidado sem predicação/objetividade nas ações profissionais/operações da equipe. Posição coerente à formação do espírito crítico/conhecimento/ área-da-enfermagem, contrária à idéia/construção-sujeitos. Sujeitos concebidos - parceirosnuma prática viva com liberdade de pensar/ ser - nas decisões em situações-problema, assistidas ou investigadas - plano/estudo/trabalho/pesquisa - abarcando interesses/ necessidades dos clientes. Destaques epistemológicos/interpretados - consistentes aos conceitos/enfermagem e idéias/autores/ referenciados, e coerência ao saber/conhecimento da Enfermagem-ciência e arte.
\end{abstract}

Palavras-chave: Conhecimento. Cuidados de Enfermagem. Enfermagem.

\begin{abstract}
Nursing as an epistemic project in the Nightingale System - teaching/ assistance/practice in health field and caring of ill/healthy people. Nurses' actions based on ethic, instructions, knowledge breaking away with pre-scientific view. Nursing - discipline/scientific practice structured in formal/material contents to the nursing care style. Criticaldiscursive approach/reflections about nursing care and the subjects' educational development leading to the constructive knowledge. Nursing as science-under-construction. Nursing care as concept/nurses' actions; epistemological inherence discussed according to the ideas/ knowledge. Emphasis on the epistemological ground to the nursing principles. Concept of care without predicative reference or objectivity in the nurses' actions and the nursing staff's work is refused. Against the idea of "construction", the focus is on the subjects as partners in real practice, thinking/acting freely, taking decisions in problematic situations in assistance/research, and considering the clients' interests/ needs in the study/work/plan. Epistemic aspects highlighted with implication in the nursing concepts and the nominated authors' ideas with consistence to the professional knowledge and coherence to the construction of Nursing - science and art.
\end{abstract}

Keywords: Knowledge. Nursing care. Nursing.

\section{Resumen}

Sobre Enfermería - proyecto epistémico/conjunto teórico-axiomático en el Sistema Nightingale/enseñanza/práctica asistencial a la salud y cuidados/enfermos y sanos. Acciones/enfermeras(os) caracterizadas en la ética, instrucciones técnicas, saber moderno rompiendo con lo saber/pre-científico. Enfermería - disciplina/práctica científica - ordenada en esquemas formales/contenidos materiales al estilo del cuidado de enfermería. Abordaje crítico-discursiva/reflexiones - cuidado de enfermería y formación de los sujetos del conocimiento/área-deenfermería. Del ángulo filosófico, la enfermería como ciencia-enconstrucción. Cuidado de enfermería discutido/concepto/actos/ operaciones/enfermeras(os), interpretado en la inherencia epistemológica/ideas - Sistema Nightingale designado solo epistemológico - concebido/analizado/estructura/fondo-de-saber y principios nightingaleanos. Posición/autora contrariaal concepto/cuidado sin predicación/objetividad en las acciones profesionales/operaciones del equipo. Posición coherente a la formación/espírito crítico/ conocimiento/área-de-enfermería, contraria a la idea/construcciónsujetos. Los sujetos concebidos - parceros en una práctica viva con la libertad de pensar/ser-, en la toma/decisiones en situaciones-problema, asistidas investigadas, en plan/estudio/trabajo/investigación, abarcando intereses/necesidades de clientes. Resaltos epistemológicos/ interpretados como consistentes/conceptos/enfermería e ideas/autores/ referenciados, y coherencia/saber/conocimiento de Enfermería-ciencia $y$ arte.

Palabras Clave: Conocimiento. Atención de Enfermería. Enfermería

'Professora Emérita UFRJ. Doutora/Docente Livre UFRJ. Professora Titular de Enfermagem de Saúde Pública EEAN/UFRJ (Aposentada). Licenciada em Filosofia UERJ. Coordenadora / Líder do Grupo da Linha de Pesquisa e Estudos Epistemológicos para a Enfermagem (Cadastros EEAN/UFRJ e CNPq). Brasil. E-mail: vilma@eean.ufrj.br 


\section{À GUISA DE PROPEDÊUTICA}

Graças aos avanços da globalização, da tecnologia digital, da alta fidelidade na comunicação de massa, e dos torpedos que expandem mensagens e imagens por todas as partes do mundo, 0 homem nos dias contemporâneos tem consciência de um mundo que se estende, independentemente, do espaço e do tempo, sendoIhe acessível o rea/pela intuição imediata e pela experiência. No plano da ciência, incluída a enfermagem, pode-se dizer que já vivemos em circunstâncias de realidade quase sem fronteiras. Os objetos corporais ou sensíveis estão aí, reduzem o horizonte do infinito ao nosso entorno e estreitam o ambiente da vida, quer nos ocupemos deles ou não. Toda a realidade émarcada pelas novidades tecnológicas e pelo impulso de mudanças velozes. Nosso ritmo agora é o da urgência, tudo ao mesmo tempo e no mesmo espaço. Com isso, o mundo é como se fosse uma realidade tecnológica existente, onde quanto mais restrita e complexa for uma idéia, ou o conceito que temos dela, mais nítida terá que ser sua distinção e a diferenciação de seus termos.

Face aos assuntos de nosso interesse, para evitar equívocos, esclareço que tenho minhas dúvidas. Não me sentindo tranqüila diante dos temas para os quais fui convidada, precisei colocálos numa espécie de roleta mental. Dispondo os termos de outra forma, pude exercitar a reflexão e pensar nas questões que percebo implicadas por detrás das idéias que me ocorrem acerca da Enfermagem - seu saber e sua história. Pude compreender, então, o que poderia elaborar como contribuição ao $60^{\circ}$. Congresso Brasileiro de Enfermagem. Em nova colocação, os assuntos - Por uma Epistemologia do Cuidado de Enfermagem e A Formação dos Sujeitos do Conhecimento na Área da Enfermagem - permitem perceber a problemática na ordem implicada que me remeteu à reflexão. E precisei de razão lógica para firmar a posição face ao interesse da Enfermagem, porém antepondo-me do ângulo de uma visão filosófica. Como dispostos no convite, os assuntos pareciam inadequados para uma elaboração de idéias e análise interpretativa. Minha posição - à guisa de propedêutica - serve aqui para assentar minhas pontuações.

Compreendo a Enfermagem como disciplina de ensino e de prática profissional com a qual, em plano epistemológico, emergiu a concepção de Florence Nightingale exarada em duas obras capitais: Notas sobre Hospitais e Notas sobre Enfermagem escritas, respectivamente, em 1858 e 1859'. Consagrada com a Escola de Treinamento para Enfermeiras, anexa ao Hospital St. Thomas de Londres (1860), a disciplina evidenciou-se como o sabere o que-fazer das novas enfermeiras, explicando-se por conceitos distintos entre a simples ordem imediata do estado pré-científico no modo de assistir aos enfermos e o estado de prática científica firmado na proposta nightingaleana de Enfermagem Moderna. Nessa proposta, a enfermagem já se inicia como conjunto, per se, de ciência, arte e filosofia (ideal), - um sistema de idéias interligando enunciados e fundamentos -, em uma teoria axiomática², perfeitamente organizada, com valor de utilidade social e significados para o que seja o cuidado de enfermos e de sãos.

A Enfermagem Moderna surgiu, assim, definindo-se por princípios e conceitos, e reunindo a um só tempo um projeto epistêmico - científico e filosófico - quanto ao ideal de rigor, à exigência da linguagem e ao requerimento vocacional. Mas já surgiu, também, como um sistema ético de nova perspectiva do cuidado à saúde, em âmbito de nova visão das coisas acerca de assistir pessoas enfermas ou sadias com carências de cuidado, de medidas de apoio e de instruções de enfermeiras especialmenteformadas, tecnicamente treinadas, para ajudar na recuperação da saúde e na manutenção da vida.

Nesses termos, a concepção de Nightingale condiz com idéias e conceitos de ações do cuidado, tão consistente com princípios básicos aos atos das enfermeiras, quanto inerente aos princípios e enunciados do modelo de ensino e de treinamento adotado para formar uma nova mentalidade profissional coerente com os significados da arte de enfermagem e com o cuidado prestado pelas enfermeiras/os. Idéias e conceitos também de regras pedagógicas tangíveis a atos de ajuda e apoio às pessoas, famílias e coletividades nos desequilibrios da saúde. Acima de tudo, reunindo conhecimentos compatíveis ao modelo de ensino e à prática assistencial e ordenando-se em esquemas de abordagem formale conteúdo material aliados aos preceitos éticos e a um estilo peculiar de prestar/ofertar o cuidado predicado como de enfermagem.

Percebo a Disciplina de Enfermagem, então, com caracteres de cunho epistemológico, posto que distinta numa ordem construída pela lógica do pensamento e da ação, e "como quebra ou dobra, nas páginas da história das enfermeiras, essas mulheres que, na era vitoriana, - segundo palavras de Cristina Miranda ${ }^{3}$-, se dedicavam a cuidar dos enfermos, dos pobres e dos loucos" e por efeito do "fazerpor-fazer", ou simples pendor caritativo.

Concebida nos enunciados nightingaleanos, em novo estilo do cuidado aos enfermos e carentes, a enfermagem moderna já surgiu explicando-se com um pensamento logicamente organizado, devidamente consubstanciado, e que se expandiu como ensino e prática por todo o mundo, - e conforme Hilton Japiassu ${ }^{4}$-, assentado em "fundo de saber devidamente constituído para ingressar no santuário da positividade científica". E constituiu-se como espécie de ruptura entre os estados de pré-saber e saber científico, ou como corte epistemológico entre "o que se fazia antes" e "o que se passou a fazer depois", a partir dos fundamentos ou princípios básicos de Nightingale.

Do ângulo filosófico, os princípios básicos da enfermagem moderna conferem como asserções primeiras do fundo de saber e do conhecimento de enfermagem. Definindo-se, então, 0 cuidado de enfermagem como objeto de estudo ou objeto de trabalho no âmbito das ações de enfermeiras/os, quer desdobradas em atos profissionais diretos, ou em operações indiretas e tarefas de distribuição para o pessoal de 
enfermagem. No todo e nas partes, ações profissionais aliadas aos objetivos de uma "ciência entendida como prática de efeito

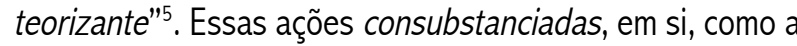
própria essência (natureza) do cuidado de enfermagem. Independentemente do apoio de outras disciplinas, a enfermagem pode bem ser compreendida - segundo Gaston Bachelard - como "ciência que é a estética da inteligência".

Devo afirmar, então, que a Enfermagem - saber e história, disciplina que ensino e da qual posso falar é a que concebo em suas vertentes - mística vocacional, movimento associativo e filosofia feminista- e que percebo assentada, por si, em uma prática científica plena de sentido estético, filosófico e social. Contudo, da concepção nightingaleana, compreendo que a Enfermagem se manifesta de modo coerente com o sentido estético o valor de utilidade social de uma pragmáticaassistencial, organizada como ordem de trabalho científico e ditames da razão. Isto, independentemente, de seu modo concreto de ser consistenteaos instrumentos metodológicos de prática social (objeto formal), ou de ser inerenteaos conteúdos espećificos do cuidado de enfermagem (objeto material). No que me interessa, e porque ancorada em ângulo filosófico, entendo a enfermagem como disciplina de aprender e de ensinar o cuidado de enfermagem, disciplina do compromisso e dos objetivos de enfermeiras(os) - profissionais habilitados em competências do pensar-saberna prevenção das enfermidades, na recuperação da saúde e na manutenção da vida. Competências acadêmicas de nível integrado na pesquisa e na produção científica.

Então, como radicada nos princípios nightingaleanos da higiene e do saneamento básico, dos fundamentos da ambiência, e enunciados de ações de assistência sanitária e vigilância de enfermagem às pessoas, famílias, coletividades, eu entendo, particularmente, que a concepção de enfermagem moderna, como transmitida, no Brasil, desde os primórdios da Missão Parsons 1922-1931 -, produziu de fato um dobramento epistemológico ou um sentido peculiar, - implicado na ordem interna das idéias -, de como cuidar e ajudar às pessoas com a saúde em estado de desequilibrio.

No conjunto e em que pese à história da profissão eà pedagogia da enfermagem de transmissão do Saber/conhecimento Profissional no Brasil', prefiro expressar meu ponto de vista consistente com a enfermagem moderna compreendida no rompimento epistemológico com noções do pré-saberde atenção aos enfermos e aos sadios. Eprefiro assumir posição coerente com as demandas de saúde dos clientes como tangíveis ao "cuidado de enfermagem".

No Brasil, a enfermagem moderna consolidou-se, como saber de cientificidade fundante não só quanto à sua "externalidade epistemológica" - nexos e conexões com outras ciências -, mas por sua "internalidade epistemológica" quanto à inerência essencial de ser uma disciplina no estilo de pensarsaber e, sobretudo, no aprofundamento e refinamento intelectual ou técnico - das bases teóricas e práticas nas obras e produtos pertinentes ao evolver do que-fazer estético e processual no que possa ser entendido como "conhecimento científico em construção's.
Não obstante "efêmera, graciosa e perene", a Arte da Enfermagem ${ }^{9}$, quer na teoria ou na prática é, sobretudo, fundada no saber/conhecimento profissiona/específico da formação da mentalidade científica, academicamente já consolidada.

\section{Por uma epistemologia do cuidado de enfermagem}

Entendo e ensino a Epistemologia como disciplina que toma as ciências como objeto de investigação. Segundo os epistemólogos ${ }^{10}$,"essa disciplina serve ao propósito de examinar, criticamente, os fundamentos e as conclusões científicas, visando determinar seu alcance e valor objetivo".

A Epistemologia abrange: a teoria do conhecimento, a filosofia das ciências (empirismo, racionalismo, etc), e a história das ciências - estudo dos fatos científicos não só em âmbito específico, ou particular, mas em sua historicidade contingente. Contudo, ela apóiase, ainda, nas disciplinas humanas ou do homem como a Psicologia e aSociologia. Ou seja, a Epistemologia carece do auxilio de outras disciplinas para tratar das ciências como objeto de conhecimento. Mas pode se aplicar aos métodos científicos e ao estudo do próprio pensamento epistemológico como dedicado às atividades da prática dos cientistas. E pode-se compreender a Epistemologia, também, como aplicada na prática da hermenêutica, esta entendida como atividade de interpretação da experiência íntima de um sujeito que se manifesta em sua produção intelectual. Seja isto como elaboração espiritual ou como reflexo de uma cosmovisãono modo de autopercepção do espíito - consciência cognoscente - que se percebee percebe o mundo em plano de filosofia de agir e de viver".

Epistemologia não é assunto de fácil síntese. Há muita confusão quanto ao uso da palavra, porém entendida como disciplina filosófica

\section{“(..) seu problema central reside nas dificuldades da definição de um estatuto geral que permita estabelecer se o conhecimento das coisas (objetos de investigação) poderá ser reduzido a um puro registro, - pelo sujeito (pesquisador) -, dos dados já anteriormente organizados, independentemente dele no mundo exterior; ou se o sujeito poderá intervir ativamente no conhecimento dos objetos"10.}

No interesse da enfermagem, penso que teremos, (quiçá), que vencer dificuldades para resolver o problema de reduzir os dados que pesquisamos, ou os resultados do que sabemos, a um puro registro. Um registro referentenão só à observação dos fenômenos, mas à analítica dos dados e à classificação dos achados, e que sobretudo convenha aos predicativos dos conceitos ou à definição do que entendemos por cuidado. Isto equivale a mergulhar a fundo na questão da verdade do conhecimento. Porém, na Epistemologia, a concepção de "verdade" se traduz em linguagem e terminologia cruciais. Ou seja, - na definição dos termos - o referenteé usado no modo predicativoe, seadequado, com valor explicativo.

Penso que, na enfermagem, ainda não se alcançou o patamar de saber resolver o problema da verdade (episteme). 
Em várias ocasiões, tenho afirmado que a enfermagem é uma ciência-em-construção. Com isto, quero dizer - segundo Abraham Moles ${ }^{11}$ - que a enfermagem é ciência-em-vias-de-sefazer. Uma ciência, porque fundamentada em concepções teóricas, em princípios básicos, em métodos de trabalho específico, e em conhecimentos de uma prática científica, legalmente reconhecida, e universalmente considerada como profissão de cuidado prestado/ofertado a pessoas enfermas ou sadias carecendo de um nível ótimo de saúde. Assim, pois, acima de tudo, uma prática profissional cientificamente fundamentada.

Todavia, à visão crítica, ainda não concebo a enfermagem capaz de reduzir o conhecimento a um puro registro, passível de compreensão por todos que subscrevem o saber/ conhecimento profissional. E se fosse, teríamos por base 0 exame detido, acurado, dos dados anteriormente organizados, independentemente de nós, ao longo dos quase cento e cinqüenta anos da história. E poderíamos avaliar, na experiência imediata, o conhecimento acumulado em seu refinamento, com precisão e clareza, para ver e comparar, como os dados já obtidos anteriormente, registrados em âmbito de conhecimento, o qual pôde avançar nos saltos evolutivos de novas aquisições teóricas. E deveríamos saber quando os dados da pesquisa precisam conservar as grandes linhas de uma episteme, ou como se diz na filosofia das ciências, nos eixos epistemológicos que demarcam o conhecimento científico em bases sólidas onde a ciência se afirma como fundo de saber ${ }^{4}$. $\mathrm{Ou}$, ainda, no sentido de um substrato essencialda generalização e "do que se afirma como descrição teórica eficaz"6.

Em sã consciência, cabe atenção ao fato de que, em nossos dias, o termo "cuidado" explodiu em uma tremenda desordem terminológica, espécie de caos epistemológico, tantas são as variações de uso da palavra "cuidado" no âmbito de várias profissões que se identificam agora como de cuidado. Pessoalmente, eu só sei falar de cuidado de enfermagem. Não me sinto à vontade para falar do "cuidado" como vocábulo de comunicação transacional, ou como termo comum empregado indistintamente por outras profissões. Haja vista que até a profissão de "médico" que, desde o século XVIII, em plano de teoria e de prática, se identificava como redutível aos atos de diagnóstico e tratamento das doenças ${ }^{12}$, mais recentemente, vem invocando e defendendo o "cuidado" como termo de sua alçada diagnóstica e espaço de perspectiva clínica na área da saúde. Não há conceito de disciplina espećfica que se sustente diante de tal "conflito" de idéias e de possibilidade polissêmica. № plano das profissões, ou de uma ciência, há que se definir o conceito do objeto-fulcrode estudo ou dado de interesse especíico, entendido como realvisado em contexto de fenômeno ou situação com sentido de problema ${ }^{13}$. Principalmente, quando diante do que se entende por verdade ou critério de busca da verdade. Afinal, é preciso admitir que "o espirito científico, às vezes, évítima das noções usuais da

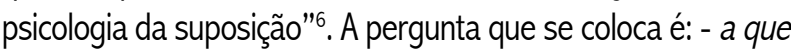
conceito ou critério de verdade o cuidado se refere?Se não houver resposta a esta pergunta, não pode haver conhecimento científico.
Se compreendo Epistemologia, então, como disciplina filosófica básica ao conhecimento científico, a Epistemologia do Cuidado da qual posso falar é a que se refere à disciplina Enfermagem cujo objeto de trabalho, no plano de enfermeiras(os), é o cuidado de enfermagem prestado aos clientes. Cuidado da responsabilidade específica de enfermeiras(os), que pode ser compreendido, focalizado, como objeto de estudo no plano da construção do conhecimento científico e, portanto, das investigações na área da enfermagem.

À maneira de ênfase, afirmo que só sei falar de "cuidado" se este for o centro de interesse objetivado em teoria e prática de enfermagem, e tal como já conceituado e assentado em "fundo de saber" espećifico do solo epistemológico - o termo é de Hilton Japiassu", - que é o próprio "Sistema Nightingale de Enfermagem Moderna". E só sei falar do que aprendi em âmbito do saber/ conhecimento profissional da enfermagem brasileira. Isto quer dizer que a epistemologia do cuidado de enfermagem da qual posso falar encontra-se enraizada nos fundamentos do Modelo Parsons, o qual implantou A Enfermagem Moderna no Brasil ${ }^{4}$.

Penso que a Epistemologia do Cuidado de Enfermagemprecisa se haver com bases teóricas, filosóficas e históricas relativas à própria Enfermagem, não só nos termos de arte pedagógica, mas entendida como prática investigativa de uma ciência-emconstrução, ou, sobretudo, como prática científica assistencial reconhecida, legalmente, no campo das ciências da saúde. Em todas as fases de um processo de trabalho assistencial, de um estudo investigativo ou nos momentos decisivos de um exame acurado, precisa-se de clareza na definição de termos. Eé preciso não perder contato com o realdo "cuidado" de que se fala. Pois, o espírito humano - entendido como consciência intelectual - precisa estar alerta, ciente de seu ângulo de posição, de sua visão teórica, da perspectiva histórica focalizada e, principalmente, do apoio de critérios que assegurem seus assentamentos e tópicos de enquadramento referencial.

Todavia, sendo pesquisadora de enfermagem, tenho procurado me manter afeita a métodos simples de investigação. Razão parajá ter tido problemas com órgãos de fomento e amparo à pesquisa. $\mathrm{E}$ sobre métodos de investigação, na área da enfermagem, penso que todos são aplicáveis desde que exeqüiveis, mesmo que sejam aprendidos e aplicados no modo artesana/de se fazer ciência ${ }^{15}$. Eis que dois caminhos são importantes para o conhecimento: a observação a descrição, dois caminhos primordiais, relevantes, para aprender sobre "o cuidado de enfermagem" e para aprender a senda adequada ao ensino eà pesquisa na área da enfermagem. Entretanto, precisamos classificar os registros compatíveis com os assentamentos relativos aos dois caminhos. Então, por isso, vale enfatizar

(...) "classificar os dados, jáanteriormente organizados, independentemente de nós ou de nossa intervenção, ou seja, é preciso lançar mão dos dadosjáassentados e constantes [também] do referencial de apoio, o que pode ajudar nas retificações das experiências imediatas [em processo], ou das buscas mais recentes". 
A classificação de dados imediatos de nossas práticas pedagógica ou investigativa - é instrumento metodológico não só para facilitar a posterior apreciação analítica, mas para firmar, de pronto, os conceitos referentes e os enquadramentos teóricos, podendo favorecer, também, às conclusões sobre os resultados obtidos. Mas prefiro pensar que os resultados, na pesquisa, mormente quando se trata do "cuidado de enfermagem", precisam do crivo de critérios de rigor e do controle de objetivos estabelecidos em processo de descrição exaustiva, culminando com definições de precisão objetiva.

Pela lente dos epistemólogos, penso que nas pesquisas sobre o cuidado de enfermagem, não se deve minimizar o conceito fundamental que caracteriza a inerência do objeto, no saber profissional, e que denota também a regra precípua para a busca de precisão e de refinamento para o conhecimento. A palavra enfermagemé crucial para a distinção entre o que ée o que não écuidado ${ }^{16}$.

\section{(...) "Ademais, seria um erro confundir o primordial} com o imediato. 0 que é imediato para uns, não o é para outros. 0 dado - [cuidado de enfermagem] - é relativo à cultura, - [em nosso caso cultura de enfermagem] - e está necessariamente inserido numa construção [teórica]. Se não tivesse nenhuma forma [distintiva], se fosse um puro e irremediável caos, a reflexão não teria nenhum poder sobre ele"6.

Posso estar falando do que todos já sabem. As teorias de enfermagem podem falar, por si, da inerência fundante, ou da internalidade epistemológica, e da historicidade da enfermagem, e são imprescindíveis pelos conceitos, regras e critérios de verdade para as buscas da ciência, se é que se deseja refinar o conhecimento profissional e o maisque possa interessar a uma epistemologia do cuidado de enfermagem. As teorias de enfermagem já ultrapassam mais de trinta contribuições explicativas para satisfazer ànecessidade de reflexão epistemológica dos que se sentem interessados no conceito de "cuidado de enfermagem".

\section{(...) "Assim, quando se coloca o conhecimento diante de sua tarefa completa de assimilação e utilização, no cerne da tradicional oposição entre dado e razão, logo se percebe que ele implica, em seu desenvolvimento e em seu objeto, um conflito íntimo que esse conhecimento não consegue jamais resolver totalmente. Sua perfeição éum limite essencial que reúne duas condições opostas: minúcia e clareza"'.}

A urgência é um fato, não precisarei realçar outros aspectos do assunto Epistemologia do Cuidado de Enfermagem. Tampouco farei maior apreciação sobre o cuidado de enfermagem em si mesmo. 0 já registrado vale de referendum ao foco central de ensino, de estudo/pesquisa, e de interesse das ações e operações assistenciais de enfermeiras(os) no campo da saúde. Também não preciso exaltar relevantes contribuições de teóricas/ enfermeiras ou pesquisadoras/escritoras de renomadas obras contemporâneas. Aliás, elas se encontram nas bibliotecas virtuais à disposição dos que desejam se haver com 0 entendimento de conceitos epistemológicos para a teoria e a prática do cuidado de responsabilidade de enfermeiras/os.

\section{A formação dos suj eitos do conhecimento na área da enfermagem}

No que tange à educação de enfermeiras(os) para a pesquisa e a produção do conhecimento, coloco-me em posição oposta, lado contrário -, aos que se propõem à "construção dos sujeitos do conhecimento". No meu modo de pensar, - do ângulo da visão filosófica- os sujeitos da aprendizagem são seres humanos que se preparam, antes de tudo, para a formação da consciência crítica faceà prestação do cuidado de enfermagem a seus clientes (também seres humanos). Razão porque não podem e não devem ser entendidos como produtos da idéia de construção. Essa idéia de "construção dos sujeitos do conhecimento" me causa certa aflição. Nos anos 1970/80, já padeci muito, na Escola de Enfermagem Anna Nery, por causa de certo Projeto "Novas Metodologias no Ensino de Enfermagem", apoiado com auxilio do então DAU/MEC e aprovado pela UFR ${ }^{17}$. Em várias ocasiões, tive a firmeza necessária para defender o assunto, sobretudo quanto ao marco conceitual do Currículo de Graduação consistente com a posição da enfermeira. Com efeito, penso que

\section{(...) "A ENFERMEIRA atua como fulcro de um PROCESSO do qual emerge a prática total da ENFERMAGEM entendida como a CIÊNCIA e a ARTE DEAJUDAR a indivíduos, grupos e comunidades, em SITUAÇÕES nas quais não estejam capacitados a provero AUTO-CUIDADO para alcançar seu nível ótimo deSAÚDE"'17.}

Naquela ocasião e em outras pelo Brasil afora, pude explicar o valor e a pertinência das palavras capitais desse marco conceitual, palavras essenciais de um conceito referente de cuidado, entendido com de ajuda na ordem implicada na atuação da enfermeira. As dificuldades de compreensão conceitual talvez persistam, mormente quanto ao sentido "epistemológico" correlato às diretrizes filosóficas, à responsabilidade social e à função primária da enfermeira. Não pretendo gastar mais tempo com detalhes sobre o assunto, apenas relevar que o "solo epistemológico" no qual esse marco se assenta é o mesmo Sistema Nightingale no qual se constitui a enfermagem moderna. Os instrumentos legais aplicados Resolução CFE No 4/72 e Parecer CFE № 57/83 -, serviram aos ajustamentos curriculares procedidos. E com as novas metodologias em torno da idéia de integração de aprender da teoria à prática, de estudar/trabalhar e de organização disciplinar de diagnosticar/investigar, pôde-se atender às mudanças objetivadas. As inovaç̃oes pedagógicas empreendidas 
- de integração curricular -, em nada alteraram "o fundo de saber" acumulado desde os primórdios da Missão Parsons (1922-1931).

Penso que os estudantes de enfermagem, como encontrados de permeio com as sendas investigativas do conhecimento, não podem e não devem ser tratados como objetos de tecnologia pedagógica artificial puramente idealizada para a construção de sujeitos de mentalidade de alta resolução. A inteligência humana já é, por si, o princípio de ordenação do cosmos. E se entendida nos termos de intellectus agens, a inteligência estudantil é atividade viva, é a faculdade do pensar e do agir capaz de organizar as sensações da aprendizagem, torná-las em percepções da realidade e transformá-las em abstrações enquanto conceitos inteligíveis, altamente referentes daquele específico cuidado de que se fala. E posso apostar, ainda, que a estrutura curricular desenhada para o Projeto "Novas Metodologias" é indiscutivelmente coerente com a formação dos sujeitos do conhecimento na área da enfermagem.

A área de conhecimento é o espaço dos espíritos intelectualizados que pensam, com independência, autonomia, no plano de uma prática viva em âmbito de tomadas de decisão com a liberdade de pensar e ser no mundo da prática dos cientistas da saúde. No ensino universitário, os estudantes de enfermagem não devem ser tratados como sujeitos capazes somente de ação passiva, ou como recursos de realizar atos e operaç̃̃es de caráter executivo, e graças à memorização de regras e preceitos estabelecidos para o que-fazerprofissional ${ }^{18}$. Penso ao contrário dos esquemas e regras de uma ideologia pedagógica de poder político exacerbado em enunciados categóricos, autoritários e ditatoriais. Por isso, percebo-me e entendo-me como adversa a qualquer espécie de pedagogia de dominação dos sujeitos da aprendizagem, ou de qualquer ideologia que se assume como capaz de realizar a construção dos sujeitos cognoscentes.

Para se haverem com as buscas investigativas, os estudantes de enfermagem precisam ser entendidos como parceiros no processo ensino-aprendizagem. Precisam se sentir com direitos aos questionamentos críticos, aos desafios de enfrentar os próprios temores e riscos e à coragem de se manifestarem diante de seus possíveis erros e de suas opiniões pessoais. Mas precisam de apoio e de ajuda pedagógica para assumir postura epistemológica no processo de aprender a pesquisar e a construir o conhecimento na área da enfermagem. Eles carecem de aprendizagem aliada às experiências da vida, uma aprendizagem que seja edificante no plano de seus estudos, de sua par ticipação assistencial e de seus projetos de iniciação científica.

Contudo, na área da enfermagem, os estudantes carecem de aprender, mediante suas próprias experiências. A busca de resposta consistente com a verdadetangível ao "cuidado de enfermagem" requer engajamento pessoal e compromisso inerente ao conhecimento do objeto de estudo. No trato com os clientes, 0 conhecimento carece de refinamento, precisão e clareza, o que nem sempre condiz com a exatidão. Entendo que na formação dos sujeitos do conhecimento - (estudantes de enfermagem) precisamos todos aprender a pensar segundo os princípios de uma filosofia do inexato. Os estudantes precisam dos objetivos de uma pedagogia de aprender-a-serou de aprender-a-tornar-se ${ }^{19}$ para que possam assimilar regras do por quee o comolidar com seu objeto de estudo/trabalho. Esse objeto designado cuidado de enfermagem encontra-se na dependência do alcance de suas próprias ações. E, se de outra forma, como poderão distintamente reconhecer, - por princípios de substancialidadee causalidade ${ }^{20}$-, a natureza essencial do cuidado de enfermagem?

Só nas dimensões de uma prática viva, os estudantes de enfermagem poderão aprender as estratégias de intervenção e decisão de pertinência para a enfermagem. E para tanto, precisam encontrar-se frente-a-frente com situaçõesproblema ${ }^{13}$, como assistidas ou investigadas, as quais em razão de seus objetivos de estudar/trabalhar englobam, certamente, os interesses e necessidades de seus clientes. À educação cabe um papel distintivo, imprescindível à compreensão das mudanças, à transmissão dos conhecimentos, ao aprendizado de condutas para o trabalho e para a vida, e à aquisição de competências para a crítica, sem o que não se pode incorporar condutas congruentes com o futuro, os desafios e dilemas sociais de nosso tempo.

Assim, quanto à "formação dos sujeitos do conhecimento na área da enfermagem", sou partidária da pedagogia da incerteza ${ }^{21}$, capaz de apoiar aos que ensinam e aos que aprendem naformação da mentalidade crítica, ou do espírito que sabe e pode enfrentar as crises das mudanças que se avizinham com o futuro. A tonalidade marcante, na área da enfermagem, para o futuro, terá que se haver com perguntas e respostas de questionamento radical "sobre enfermagem - ensino e perfil profissional", com a grande implicação no cuidado de enfermagem. A pergunta que se coloca é: - a quem pode interessar a enfermagem-ciência no futuro: - aos cientistas ou aDeus?

\section{A TÍTULO DE CONCLUSÃO}

Não pretendo responder à causticante pergunta. Contudo, algumas conjeturas alimentam, ainda, minhas reflexões acerca de uma possível nova ordem na ciência. Os colegas ou parceiros de mentalidade brilhante talvez possam se beneficiar. Mas que fique assentado: - esta parte de minha contribuição é mais fruto de devaneio utópico do que produto de opinião filosófica. Fato é que se, no futuro, o cuidado de enfermagem e a formação dos sujeitos do conhecimento puderem ainda interessar, - como temática e problemática -, às ações de enfermeiras/os, então os desafios consistentes com epistemologiae educação, com certeza nos farão enfrentar novos paradoxos. Ao invés dos parâmetros entendidos para a "ciência-baseada-em-evidências", as pesquisas terão que se haver, quiçá, não só com proposiç̃̃es teóricas e princípios cientíicos, mas também com significados polissêmicos de conceitos referentesà compreensão da imagem/objetonos termos do novo paradigma holográfico. 
Minha compreensão desse assunto é quase nula. Não posso afirmar se tudo acontecerá como os próprios cientistas discutem ciência pura e misticismo. Fato é que, "a partir de 1970, o diálogo científico tornou-se amplo com cientistas de várias áreas, como se estivessem falando religião, e tentando explicar os dados hard da própria ciência. Eles diziam: - (...) os fatos reais, efetivos, da ciência só parecem fazer sentido se presumimos algum tipo de fundamento implícito ou unificador, ou transcendental subjacente aos dados explícitos"22. Em vista da perspectiva de interface entre ciência e religião, ou de mudança de paradigma percebo que

(...) "a nova ordem holográfica apresenta interesse especial. Seu domínio relaciona-se com a idéia da imagem/objeto implicando em distintas operações mentais - (a exemplo das evidências e das matemáticas) - refletindo a ordem básica do universo; o tempo e o espaço colapsam no domínio das freqüências"22.

No caso de pesquisas "sobre enfermagem - ensino e perfil profissional", - seguindo a ordem do paradigma holográfico -,

(...) "as habituais fronteiras do espaço e do tempo, as localizações nas situações humanas ou nas circunstâncias históricas, ficam suspensas e devem ser lidas quando se efetuam transformações para o domínio imagem/objeto. Na ausência de coordenadas de espaço-tempo, o sentido usual de causalidade, também deve ser suspenso. Deve-se recorrer, então, a complementaridades, sincronicidades, simetrias e dualidades, à guisa de princípios explanatórios"²3.

E, então, as ações investigativas para o cuidado de enfermagem (objeto de estudo), podem conduzir o espírito humano - sujeito cognoscente - na direção de si mesmo, e este poderá se achar como transcendente aos dados, mas no mesmo holograma, podendo refletir a unidade subjetiva na diversidade dos dados objetivos. E, nesse caso, impõem-se as regras de uma nova ciência capaz de definir o próprio pensamento como presciência- uma ciência que é antes de tudo. Eum pensamento da ordem do espírito transcendental capaz de explicitar como os dados existentes na diversidade objetiva (parte positiva), podem estar no todo da pesquisa, e como o todo da pesquisa pode estar em cada parte; pensamento que seja capaz de compreender que "o ponto-chave de um problema reside simplesmente no fato de que a parte tem acesso ao todo"z2.

Para abranger tal compreensão, será preciso contar com a aprendizagem de uma educação nova ou renovada, e dos conceitos holísticos de uma enfermagem básica, fundamental, à compreensão da urgência de novas estratégias para o cuidado de enfermagem. Uma educação coerente à ação dinâmica dos coordenadores, aos critérios de rigor e à responsabilidade social solidária, pautada na faculdade intelectual e na capacidade pedagógica tecnicamente habilitada dos empreendedores de mudanças ${ }^{24}$. Mais do antes, convém atentar para o fato de que

(...) "os sujeitos [do conhecimento] estão aí com carências de aprender que a educação não é um mero ensinar o já sabido, transmitir o já estabelecido, ou um puro veicular de informações que não formam, e a reproduzir o já produzido. 0 novo sujeito não deve ser impedido de pensar. 0 pensamento é um trabalho"'t.

Mas falo dos sujeitos do conhecimento entendidos como estudantes de enfermagem, - seres humanos dotados espiritualmente de consciência cognoscente-, capazes de aprender com seus mestres a superar obstáculos epistemológicos, de obter novos dados e de fazer retificações em suas experiências, de enfrentar os paradoxos da nova ciência e de buscar respostas alternativas para formular ou reformular hipóteses de trabalho fundamentais à construção do conhecimento eàs novas explicações para os seus achados. Neste sentido, é que preciso admitir, de uma vez, que sou completamente adversa à idéia da construção dos sujeitos do conhecimento.

A construção de objetos ou produtos científicos, no plano do tema "a formação dos sujeitos do conhecimento na área da enfermagem", requer não só o apoio de uma filosofia crítica, mas a autonomia de uma postura epistemológica demarcante da experiência viva de lidar com "o homem e o social", e de aprender a pesquisar consistentemente com a teoria do conhecimento ${ }^{20} .0$ que requer, sobretudo, os recursos de uma pedagogia para 0 homem ${ }^{24}$, favorável à mentalidade dos que se aplicam por uma hermenêutica na apreciação justa de mudanças da época e de tendências do futuro. Para isso, (...) "é preciso atenção às novas diretrizes educacionais [positivadas no homem] e aos objetivos flexíveis e de perspectivas abertas"25. É quando mais precisamos enfrentar o desafio de assumir posição frente à necessidade de formar mentalidades profissionais para hoje e amanhã. Na área da enfermagem, a formação do espirito científic ${ }^{6}$ exige conhecimento de disciplinas espećificas e conexas, de filosofia e de história, e de outras que se ajustem aos requisitos profissionais como apoio digno do saber coerente a uma postura epistemológica em face dos resultados das ciências. Os interesses e os objetivos da prática de ensinar, de assistir e de pesquisar precisam abarcar suporte para a realidade de pensare serno mundo e na realidade da ciência. Só assim, os sujeitos do conhecimento podem ser formados - espiritos cognoscentes - para assumir papel e responsabilidade social na área da enfermagem.

A era da tecnologia acarreta incontáveis e indiscutíveis benefícios e abre amplas perspectivas quanto ao presente e ao futuro, mas tem também seus inconvenientes. Sobre isso não há mais segredos. Está tudo aí, em público, para 
qualquer um aprender e discutir. Mas é preciso atentar que os novos sujeitos possam aprender, desde cedo, as regras do jogo no plano das ciências e na emergência mesma das situações da vida.

Daí as exigências de uma nova educação consistente com o cultivo das linhas de pesquisa ou que seja pelo menos renovada nos termos dos núcleos de pesquisa projetados no interesse da disciplina de Enfermagem - seu saber e sua história. Do ângulo da visão filosófica, penso em uma educação que, para se haver com "a formação dos sujeitos do conhecimento na área da enfermagem", precisa de coerência com o princípio da realidade da vida e das incertezas da ciência. Uma educação nova, ou renovada, talvez careça de revisão de objetivos favoráveis à superação de dificuldades epistemológicas. Mas uma revisão também de interesses pragmático-assistenciais, posto que os cenários dos campos de estágios para os estudantes de enfermagem a cada dia parecem mais reduzidos e, com efeito, são ainda o melhor laboratório para as pesquisas de enfermagem.
Sou otimista quanto ao futuro e, por isso, sempre penso em uma educação capaz de abranger a subjetividade no conhecimento integrada dialeticamente à própria vida. E penso que os sujeitos do conhecimento na área da enfermagem precisam ser formados para atuar em âmbito de prática substantiva, prática total de visão planetária em face de um mundo de mudanças velozes e que já se planifica para o domínio dos caminhos que conduzem às estrelas. Na realidade social, é unânime a opinião de que os mais pobres vivem à margem de seus direitos de cidadania e morrem bem mais cedo e sem as primícias do trabalho, da educação e dos serviços de saúde.

Não pretendo me adentrar pelos meandros das injustiças sociais, oriundas que são de políticas inadequadas. Porém, como há muita imobilidade entravando o progresso educacional, nos cenários universitários, onde são formados os sujeitos do conhecimento, penso que é imperativo redefinir-se a atividade pedagógicoeducativa de modo a compreender a formação desses mesmos sujeitos no plano do novo espírito científico capaz de abarcar, da mesmaforma, os significados de pertinência do saber/conhecimento profissionalconsistentemente com a Enfermagem-ciênciae arte.

\section{Nota}

a Trabalho/Mesa Redonda 1 "Epistemologia do cuidado e construção dos sujeitos do conhecimento" - $60^{\circ}$ Congresso Brasileiro de Enfermagem, Belo Horizonte MG - 03 a 06 de novembro de 2008.

\section{Referências}

1. Seymer LR, organizador. Selected writings of Florence Nightingale. New York (USA): The Macmillan Company; 1954.

2. Carvalho V. Cuidando, pesquisando e ensinando: acerca de significados e implicações na prática da enfermagem. Rev Latino-am Enfermagem 2004 set/out; 12(5): 806-15.

3. Miranda CML. 0 risco e o bordado: um estudo sobre formação de identidade profissional. Rio de Janeiro (RJ): EEAN/UFRJ; 1996.

4. Japiassu H. Nascimento e morte das ciências humanas. $2^{\mathrm{a} e d .}$ Rio de Janeiro (RJ): Francisco Alves ;1982.

5. Carvalho V. Acerca de las bases teóricas, filosóficas, epistemológicas de la investigación: el caso de la enfermería. Rev Latino-am Enfermagem 2003 nov/dez; 11(6): 807-15.

6. Bachelard G. A formação do espírito científico. Rio de Janeiro (RJ): Contraponto; 1996.

7. Paim L, Carvalho V, Sauthier J. 0 saber/conhecimento profissiona na enfermagem brasileira: comentários sobre momentos decisivos na trajetória histórico-evolutiva. ABEn- J Assoc Bras Enferm 2003; $45(3-4)$

8. Carvalho V. Enfermagem e história da enfermagem: aspectos epistemológicos destacados na construção do conhecimento profissional. Esc Anna Nery Rev Enferm 2007 set; 11(3): 500- 08.

9. Caccavo PV, Carvalho V. A arte da enfermagem: efêmera, graciosa e perene. Rio de Janeiro (RJ): EEAN/UFRJ; 2003.

10. Japiassu H. Introdução ao pensamento epistemológico. $2^{\mathrm{a}}$ ed. Rio de Janeiro (RJ): Francisco Alves; 1977.
11. Moles AA. As ciências do impreciso. Colaboração de Elisabeth Rohmer. Tradução de Glória de Carvalho Lins. Rio de Janeiro (RJ): Civilização Brasileira; 1995.

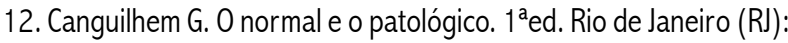
Forense Universitária; 1978.

13. Carvalho V. Sobre o projeto para aplicação de novas metodologias ao processo ensino-aprendizagem: a experiência de mudança curricular na graduação da EEAN/UFRJ. In: Carvalho V, organizadora. Sobre enfermagem: ensino e perfil profissional. Prefácio de Lygia

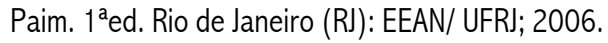

14. Parsons E. A enfermagem moderna no Brasil. [fac-símile]. Esc Anna Nery Rev Enferm 1997 jul; 1 (n esp lanç): 09-24.

15. Becker HS. Métodos de pesquisa em ciências sociais. $4^{\mathrm{a} e d .}$ Tradução de Marco Estevão e Renato Aguiar. São Paulo (SP): Hucitec; 1999.

16. Nightingale, F. Notas sobre enfermagem: o que é e o que não é. Prefácio de leda Barreira e Castro. Tradução de Amália Corrêa de Carvalho. São Paulo (SP): Cortez; 1989.

17. Carvalho V, Castro IB, Paixão SS. Um projeto de mudança curricular no ensino de enfermagem em nível de graduação que favorece aos propósitos emergentes da prática profissional. Anais do $30^{\circ}$ Congresso Brasileiro de Enfermagem; 1978 jul 16-22; Belém (PA), Brasil. Belém (PA): ABEn; 1978.

18. Carvalho V. Dimensões do saber-fazer do enfermeiro que fundamentam o conteúdo do currículo de graduação: uma contribuição 
à identidade profissional. São Paulo (SP): Frontis; 1996. Trabalho apresentado originalmente no Encontro Nacional de Escolas de Enfermagem-ENESC realizado pelo Departamento de Enfermagem/ UNIFESP, com apoio da ABEn - Seção SP.

19. Faure E. Aprender a ser. Tradução de Maria Helena Cavaco e Natércia Paiva Lomba. São Paulo (SP): UNESCO/Difusão; 1972.

20. Hessen J. Teoria do conhecimento. Tradução de João Vergílio Gallerani Cuter. São Paulo (SP): Martins Fontes; 1999.

21. Japiassu H. Pedagogia da incerteza e outros estudos. Rio de Janeiro (RJ): Imago; 1983.
22. Wilber Ken, organizador. 0 paradigma holográfico e outros paradoxos: uma investigação nas fronteiras da ciência. $10^{\mathrm{a}}$ ed. Tradução Maria de Lourdes Eichenberger e Newton Roberval Eichemberg. São Paulo (SP): Cultrix; 1995.

23. Pribram KH. Qual a confusão que está por toda a parte. In: Wilber Ken, organizador. 0 paradigma holográfico e outros paradoxos: uma investigação nas fronteiras da ciência. $10^{\mathrm{a}}$ ed. Tradução de Maria de Lourdes Eichenberger e Newton Roberval Eichemberg. São Paulo (SP): Cultrix; 1995.

24. Etave R. Uma pedagogia para o homem. Petrópolis (RJ): Vozes/ FUM; 1971. 